\title{
The Art of Wellbeing: A Public Health Perspective
}

\author{
By Robin Philipp* \\ Pamela Thornet
}

\begin{abstract}
The field of arts and health explores the many ways in which the arts can be used to improve health by promoting wellbeing. Since the arts and health movement began in the latter half of the twentieth century, it has consolidated its methodology through networks to disseminate research and good practice, begun to build a credible evidence base through collaborative work with academic departments and extended its application with multi-agency working. Since the turn of the century the movement has expanded to include a special focus on heritage and culture, aspects of the arts which are significant in the building of social capital and both community and personal wellbeing. Recognition of the benefits of the arts by the United Kingdom (UK) government has seen it established in health and social policy decisions as a means of tackling health inequalities. The UK based Royal Society for Public Health (RSPH) has taken a lead in helping to progress developments in this area. It does this through its journals, courses and Award schemes, and a recently formed Special Interest Group. This paper outlines the work of the RSPH in this field to date. It then presents a viewpoint on some recent developments in wider applications for the arts and culture, across a spectrum of health and wellbeing.
\end{abstract}

Keywords: Arts and health, Cultural capital, Public health, Social capital, Wellbeing

\section{Introduction}

The Royal Society for Public Health (RSPH) in England has supported the field of arts and health for many years. In preparation for the first international conference on Culture, Health \& Wellbeing in Bristol, UK in 2013, it convened a working group to compile an overview of the field in the fifteen years since the seminal Windsor conferences on arts and health, convened by the Nuffield Trust in 1998 and 1999 (Philipp et al. 1999, Philipp 2002). Interest in using the arts for health and wellbeing burgeoned in the second half of the twentieth century, as it became apparent that, in spite of many advances in scientific knowledge and technology, conventional medicine was not meeting people's need for "complete physical, mental and social well-being" as described in the World Health Organisation's 1948 definition of health ${ }^{1}$. Increasing levels of functional illness with no apparent organic basis caused the focus of healthcare to move from the disease-based medical model to primary prevention and health promotion. In response to the increasing inequalities in health reported by the government white paper Health of the Nation 1992 (Secretary of State for Health 1992), public health policy adopted a "healthy settings" approach based on the 1980s WHO global strategy Health for All, which suggested that health is created and lived by

\footnotetext{
${ }^{*}$ Honorary Consultant Occupational and Public Health Physician, University Hospitals Bristol NHS FoundationTrust, UK \& Centre for Health in Employment and the Environment (CHEE), Occupational Health Service, Bristol Royal Infirmary, UK.

${ }^{\dagger}$ Research Psychologist, Centre for Health in Employment and the Environment (CHEE), Bristol Royal Infirmary, UK.

${ }^{1}$ WHO (1948) Constitution of the World Health Organisation. Retrieved from https://bit.ly/2H qJXn1.
} 
people within the settings of their everyday life, where they learn, work, play and live (WHO 1981). Healthy Living Centres (HLCs) were created in some of the most deprived sections of the population, with the aim of providing opportunities to improve quality of life and enable people to achieve their full potential (NHS Executive 1999). Many of the range of opportunities for promoting health and wellbeing which were offered involved the arts. At a personal level, measurable health benefits of participating in creative arts activity included (Health Education Authority 2000):

- Enhanced motivation;

- Greater connectedness to others;

- Perceptions of having a more positive outlook on life;

- Reduced sense of fear, isolation and anxiety; and

- Increased confidence, sociability and self-esteem.

Benefits which arts projects brought to the community as a whole included (Goodlad et al. 2002):

- The opportunity for people to meet together with a common purpose;

- Enhanced communication between groups and individuals; and

- Improved trust between individuals and government institutions.

It became clear that the arts were a useful tool for improving public health, tackling social inequalities and promoting social inclusion, which merited further evaluation (Hamilton et al. 2003). Against this background, the Windsor conferences brought together people from the health professions, the arts, philosophy and theology to lay the foundations of a strategy which would "promote the arts from the margins into the very heart of healthcare planning, policy-making and practice" (Philipp et al. 1999).

Fifteen years on, it was apparent from the RSPH overview, entitled Arts, Health and Wellbeing beyond the Millennium: How far have we come and where do we want to go $?^{1}$ that the arts had indeed become an established part of health and social policy and practice, with much new expertise in the field. In 2010 the Marmot Review of health inequalities and the social determinants of health, had once again brought health and wellbeing to the forefront of public health strategy, both in the UK and internationally (Marmot Review Team 2010). In the UK health was no longer seen as the sole responsibility of the National Health Service (NHS), which, it was pointed out (Marmot \& Bell 2012), could not tackle health inequalities alone, but required local authorities and third sector agencies to work together in partnership to create healthy communities. Numerous preventive interventions using the creative arts showed important benefits ${ }^{2}$, and multi-agency working extended to collaboration with

\footnotetext{
${ }^{1}$ Arts, Health and Wellbeing Beyond the Millennium: How far have we come and where do we want to go? Retrieved from fhttps://bit.ly/2qTvwUD.

${ }^{2}$ Ibid.
} 
academic research units, which crucially raised the quality of evaluation of such projects and began to build a robust evidence base. Examples of such projects are show-cased in the report, which can be found on the RSPH website ${ }^{1}$.

The RSPH has continued its support of the arts and health field through its journals, training courses and an annual Arts for Health Award scheme, now part of the wider focused Health and Wellbeing awards. It has also built on an important element of the progress made to date in multidisciplinary collaboration by forming a Special Interest Group (SIG) for Arts, Wellbeing and Health, which incorporates the UK Arts and Health Research Network. The collaboration provides a sustainable way forward for this successful group. One research partner of the SIG is Lord Howarth of Newport, a long term supporter of the field, who is co-chair of the UK Government All Party Parliamentary Group on Arts Health and Wellbeing (APPGAHW) which provides a forum for discussion between politicians and practitioners to inform policy development. The APPG maintains close links to the National Alliance for Arts, Health and Wellbeing which in the UK coordinates the dissemination of research findings and best practice. The APPG's first project was to carry out an Inquiry, building on the conclusions and recommendations of the RSPH report ${ }^{2}$. It was intended to lead to a report, to be presented at the 2017 international Culture, Health and Wellbeing conference, which would provide an update on progress in the arts and health field and include policy recommendations ${ }^{3}$.

This paper explores new directions now emerging for arts and health. They include developments that can be adopted by individuals, communities and organisations.

\section{New Directions for Arts and Health}

The RSPH's Arts, Health and Wellbeing beyond the Millennium report ${ }^{4}$ marked a milestone in the field of arts and health. It updated the Nuffield Trust's earlier initiative, providing an overview of the immensely encouraging progress which has been made, particularly in research methods to improve the evidence base. Importantly, it also provided a platform for new thinking around future directions for arts and health which has helped to widen its application across a spectrum of health and wellbeing, for both individuals and communities, and strengthen further links with medical humanities. The earlier Nuffield Trust work had described the medical humanities as being a discipline engaged in "compassionate concern for the advancement of mankind's welfare".

In Bristol, UK, the Bristol Royal Infirmary-based Centre for Health in Employment and the Environment (CHEE) has been working closely with the

\footnotetext{
${ }^{1}$ Ibid.

${ }^{2}$ Ibid.

${ }^{3}$ The All Party Parliamentary Group on Arts, Health and Wellbeing, 2017. Creative Health: The Arts for Health and Wellbeing. Retrieved from https://bit.ly/2vCJQWA.

${ }^{4}$ Arts, Health and Wellbeing Beyond the Millennium: How far have we come and where do we want to go? Retrieved from fhttps://bit.ly/2qTvwUD.
} 
RSPH and the Philipp Family Foundation (PFF), a New Zealand-based charitable trust (Philipp et al. 2012). The focus of this work has been to explore some of the wider dimensions of health and wellbeing. These dimensions were first presented in the final sections of the RSPH report, applying the "arts-science spectrum of inquiry", a framework developed in earlier work for the WHO and Nuffield Trust (Philipp et al. 2012). The framework recognizes the value of both science and arts paradigms spanning from the subjective, intuitive, individually inspirational, artistically expressive viewpoints, to the objective, measurable, productive, logical and scientific perspective. The two approaches are interconnected and both are essential if the fullest possible understanding of "what is going on" is to be achieved. Traditionally, the NHS has expected to base funding and policy decisions on evidence from the gold standard method of randomised controlled trials ${ }^{1}$ which are not easily applied in community settings. But whereas at one time participants' own words would have been considered "anecdotal" and of little value, they have come to be valued as "serious personal testimony" (Cameron et al. 2013). Professor George Salmond, former Director General of Health, New Zealand, put it this way: "If progress is to be made in improving the nation's health, new concepts, knowledge and skills must be introduced. Analyses are needed which would break away from the narrow confines of biomedicine and economic rationalisation, and which encompass more socially and ecologically conscious constructs. The latter would empower people and involve communities in democratic approaches aimed at enhancing well-being and health status" (Mooney 1995).

In the arts, health and wellbeing field as it applies to the public health, subjective opinions are particularly useful. Whereas the value of ideas as judged by the scientific community does not necessarily always lead to practical, worthwhile ideas for the wider community, freeing the mind and building thinking connections across society can help to build shared, innovative programmes ${ }^{2}$. Qualitative methodology using creative thinking and problem solving based on subjective viewpoints has also been usefully applied alongside quantitative data analysis in other interdependent areas such as conservation; heritage; ecology; and social, environmental, and humanitarian issues (Philipp et al. 2012). These are areas which have been of long-standing interest to the PFF, one of whose principal aims is to help foster the development and exchange of relevant information in support of the public health. In partnership with a wide range of other organisations it aims to enhance wellbeing by helping people at a personal, individual level to be comfortable in their identities, to find meaning in their lives and feel part of rather than apart from what goes on around them, and to have optimism. It has as its motto the aphorism "Everything in life is connected" which is intended to encapsulate the interdependence for health and wellbeing of human, environmental, conservation, ecological, heritage and aesthetic factors. The objectives of the PFF encompass these areas and their relationships (Philipp et al. 2012).

${ }^{1}$ Ibid.
${ }^{2}$ Ibid. 


\section{Valuing the Many Facets of Health and Wellbeing}

An individual's health has physical, psychological, emotional and spiritual parameters, and is influenced in turn by economic, cultural, social and environmental factors in the community. The WHO European Charter on Environment and Health stated that: "Good health and wellbeing require a clean and harmonious environment in which physical, psychological, social and aesthetic factors are all given their due importance" ${ }^{1}$ and it further states that "each individual has a responsibility to contribute to the protection of the environment, in the interests of his or her own health and the health of others". This concept of reciprocal maintenance, or looking after the things that look after us, is the basis of sustainability and the principle that in developing and using the natural resources of our planet, each generation should meet the needs of the present without compromising the ability of future generations to meet their own needs (Philipp \& Thorne 2015). It is therefore part of health promotion and public health policy that natural environments and natural resources should be protected, and their links to health, wellbeing and social justice need to be better understood. It has been pointed out that these connections have not been sufficiently valued by the health sector (Porritt 2012).

The appreciation and enjoyment of beauty is an important component of emotional and environmental wellbeing. Although difficult to define, it is closely related to aesthetics and can be thought of as being a characteristic of a person, animal, place, object or idea that provides an inner, personal experience of pleasure or satisfaction. Experiencing it often involves finding for ourselves that something seems to be in balance and harmony with nature, that we are attracted to it, and that we find it pleasing (Philipp et al. 2013). Indeed, many studies have shown that we feel better and healthier when we spend time close to nature: mentally, emotionally, psychologically, physically and even spiritually. These benefits can include increased energy, relaxation, a sense of connection, and happiness (Philipp 2012). The way in which we look outwards at the world influences our perception of it and response to it, in a dynamic and symbiotic relationship based on the values we hold (Philipp 2007). Unfortunately, many activities valued in modern society bring "happiness" only in the short term, and are a threat to our health and wellbeing over time. These include lifestyle choices such as cigarette smoking, abuse of alcohol or drugs and sedentary lifestyles which provide some of the main challenges for public health in the West. Regrettably, efforts to change people's thinking and support the public health have to contend with powerful organisations driven by a profit motive.

Taking personal responsibility for our wellbeing involves a reassessment of personal values which can lead to a healthier and happier lifestyle. From an exploration of the basis of human values undertaken for the Nuffield Trust, WHO, and Office for International Health Co-Operation and Development of the Italian Red Cross, an anthropological framework has been produced (Philipp 2007). It includes four core components of relevance to wellbeing:

${ }^{1}$ WHO (1989) European Charter on the Environment and Health. Retrieved from https://bit.ly/2qS MmlM. 
- Appreciation of different civilisations, cultures, customs and societies;

- Awareness of tools a society develops for its sense of place, purpose and security;

- Knowing what influences thinking and perceptions among members of a group; and

- Linking our external experiences with our internal feelings.

Reappraising our value systems to give health its rightful place as our true "wealth" involves improving personal attitudes, outlook and behaviour and promulgating a sense of global citizenship, with the benefits which that could bring. It extends the WHO concept of "healthy settings" to what has been termed "healthy outlooks", the suggested aim of which is "to improve awareness and understanding of the term wellbeing and what we can each do to better access and appreciate $i t^{\prime 1}$ (Philipp 2010). This aim builds on increasing awareness that individuals must accept more responsibility and accountability for their own health and happiness. A better understanding of the interdependent relationship between factors in the external world and our individual responses to them would help people to see that creative endeavour and aesthetic appreciation can benefit morale, self-esteem, confidence, wellbeing, sense of belonging and personal development, thus adding pleasure, purpose and meaning to our lives (Philipp 2012). This has been termed "the art of wellbeing" (Philipp 2012), involving as it does "the application of creative skill and imagination" (English Oxford Dictionary). It can be fostered.

\section{Strengthening Social and Cultural Capital through New Links: The Example of Museums and Art Galleries}

A relatively new area in the field of arts and health, which is contributing to the reappraisal of values, is the culture and heritage sector. Museums and galleries for example have always played a role in education but are now being mined for their potential in promoting cultural and social capital. Cultural capital has been defined as "the wealth created through celebrating and investing in cultural history, values, ideologies, rituals and programmes" (Eames 2007, Eames 2003) and it can strengthen identity at an individual and community level. Social capital is also an important indicator for public health ${ }^{2}$ and encompasses the human factors of talent, capability, creativity, innovation and knowledge, and the extent of relationships, social networks and civic engagement (Eames 2003). All these factors contribute to the enhancement of community cohesion and lead to more resilient individuals and communities. Social capital is strengthened by social inclusion ${ }^{3}$, an early objective of arts interventions (Hamilton et al. 2003) and a key focus of the UK public mental health framework Confident

\footnotetext{
${ }^{1}$ Arts, Health and Wellbeing Beyond the Millennium: How far have we come and where do we want to go? Retrieved from fhttps://bit.ly/2qTvwUD.

${ }^{2}$ Ibid.

${ }^{3}$ Ibid.
} 
Communities, Brighter Futures (Department of Health 2010). The framework includes proposals for interventions involving the arts and creativity which engage both individuals and communities with the aim of enhancing social capital and building social networks. Community resources such as galleries and museums provide an opportunity for partnership working between primary care, local authorities and the third sector to tackle health inequalities and attract people who might not have traditionally used such facilities. Museums offer a non-stigmatising setting where people can be encouraged to "learn about themselves, their culture and society, and the larger world around them" (Camic and Chatterjee 2013).

In 2008 the UK government's Foresight project on Mental Capital and Wellbeing commissioned the New Economics Foundation to develop a set of five, simple, evidence-based actions which could be built into people's everyday lives to promote positive mental health: Connect, Be Active, Take Notice, Keep Learning, Give (Aked and Thompson 2011). Participating in a community programme in a museum provides the opportunity for people who may never have entered a museum or gallery before to achieve the first four of these 5 ways to wellbeing. Many museums also run volunteer programmes which offer the opportunity to "Give". There is evidence that volunteering has physical and mental benefits (Grimm et al. 2007).

In the UK, the Group for Education in Museums, (GEM), is also keen to promote the benefits to health and wellbeing of museum visits and values and value systems. It was one of the topics discussed at their 2015 annual conference (Philipp and Thorne 2015). As reported recently by the RSPH, there is a need for more "health promoting" businesses, such as museums and art galleries in our town centres ${ }^{1}$. A joint project is currently being planned with GEM to explore expressions of wellbeing in museum artefacts and projects, and produce an educational resource which will support the public health.

\section{The Holistic Nature of Wellbeing}

The 5 ways to wellbeing published by the New Economics Foundation (Aked and Thompson 2011) are techniques individuals can use to help themselves improve their mental health, in a similar way to physical health promotion campaigns such as "5-a-day" healthy eating. Holistic healthcare is a broader approach that seeks to treat the mind and spirit as well as the body (Philipp 2012) and better understanding of the interdependence of the various parameters of health has led to mental health being now considered as important as physical health. Even ancient civilisations understood the importance to health of achieving a natural balance between people's body systems, their lifestyle and their environment, believing for example that illness was an imbalance between the four bodily humors: blood, phlegm, yellow bile and black bile which were in turn linked both to the seasons, and to the elements of earth, air, fire and water

${ }^{1}$ Health on the High Street (2015) Royal Society for Public Health, London. Retrieved from https://bit.ly/2fbRNHo. 
(Philipp 2012). This idea of bodily harmony in tune with its environment survives today in ancient medical systems such as Ayurvedic medicine and Chinese medicine, and in the more recent "integrated medicine" which pays attention to body, mind and spirit and the influence of lifestyle factors and relationships (Rees and Weil 2001). The western world is increasingly adopting elements of these systems. For example, mental wellbeing has been defined by NHS Health Scotland as "a broad term encompassing areas such as life satisfaction, optimism, self-esteem, mastery and feeling in control, having a purpose in life, and a sense of belonging and support" (Philipp and Thorne 2015). Associated with this framework, there is a growing awareness and appreciation that there is an art to achieving this sense of mental wellbeing (Philipp et al. 2013).

\section{Encouraging Social Inclusion}

Social inclusion through the arts is increasingly considered to help population groups who are marginalized, disenfranchised, or otherwise excluded due to racial, ethnic, religious, cultural or gender issues. Arts-based activities can be particularly supportive of issues surrounding identity, such as a sense of belonging and being part of a community. There are associated gains for self-esteem, confidence and morale (Philipp 1999). Our sense of identity is central to our wellbeing, and where we have come from and where we belong are particularly relevant in the current "global" world. Recently in Bristol, UK, which received the "City of Sanctuary" award in 2011 and is now home to people from numerous cultures, an exhibition to explore this sense of identity was staged on the open space in front of City Hall. It comprised contributions from citizens on the themes of Home, Histories and Hope. These, in the form of words and pictures, were printed on A-framed "tents" which covered the green, bringing to mind the transit camps for refugees through which many of Bristol's asylum seekers may have travelled. Entitled "Portents", this 10-day event attracted over 11,000 visitors, 434 of whose responses to the exhibits were captured and analysed. The free-text reflections from these visitors, on the three themes of the event, addressed hope (72\%) much more frequently than home $(49 \%)$ or histories $(21 \%)$. Responses were mostly positive, the principal hope being for opportunities for themselves and others to be able to enjoy life more and in non-material ways (Philipp et al. 2015a). In our present unsettled times the importance of hope, which has been shown to be related to measures of better health and wellbeing and lower psychological distress (Coughlin 2006) is perhaps summed up by the respondent who wrote: "Hope is the optimistic force propelling us through our darkest days on towards brighter and better days." The findings of this study were used to model an educational tool for social and cultural capital (Philipp et al. 2015a) linked to the anthropological framework for the basis of human values described above (Philipp 2007). Aimed particularly at support for new immigrants, refugees and asylum seekers, this tool is intended to help build a culture of hospitality, reducing aculturalisation (a sense of loss, aloneness and of feeling apart) and strengthening social cohesion. The framework includes practical guidelines for supporting refugees and asylum seekers and helping them to adjust to their adopted country, 
including acquisition of language skills and understanding of entitlement to health and social care. It also suggests training in cultural awareness, to include information about different ethnic groups and to further understanding of the importance of the concept of culture and its contribution to health and wellbeing. Compassion has a key role in this understanding. It is an essential component in the art of wellbeing and deserves further study.

\section{Core Values and Standards: the Role of Compassion in the Art of Wellbeing}

A common set of core values and standards is considered essential for the culture of "patient first" healthcare to which the British NHS aspires and these are set out in the NHS Constitution ${ }^{1}$. The original intention of the Constitution was to help bring about a culture shift in the organisation, from an emphasis on productivity to a focus on supporting and empowering frontline staff in order to improve the quality of care and make it "clinically effective, personal and safe" (Lord Darzi 2008). Recent publicised failings in a few healthcare trusts led to a major initiative across the NHS to endorse the concept of shared values and prompted us to undertake a point-prevalence audit of expressions of the six NHS Constitution values on the websites of Healthcare Trusts in two regions of England (Adcroft et al. 2014). Those values are: Working together for patients; Respect and dignity; Commitment to quality of care; Compassion; Improving lives; Everyone counts. Surprisingly for a healthcare setting, our audit showed that the value least often expressed by trusts in either region was Compassion, found on $73 \%$ of Trust websites in one region but only $36 \%$ of Trust websites in the other region.

Compassion appears not only as a Constitution value but as one of the fundamental values which underpin the UK's vision and strategy for nurses, midwives and care staff $^{2}$, the 6 C's: care, compassion, competence, communication, courage and commitment. It is a term synonymous with humanity itself. One objective of the earlier Arts and Health conferences at Windsor, UK was to embed medical humanities in the undergraduate curriculum and in continuing medical education because it was felt that "Medical students should be given the opportunity to study the humanities during their undergraduate education to help them develop a more compassionate understanding of the individual in society, to inspire empathy with patients and colleagues, and to become more "rounded" people themselves" (Philipp et al. 1999). Fascination with scientific and technological advances and rigid scientific medical education were believed to have contributed to the diminishing of empathy and compassion in the practice of healthcare, and health planners and health economists saw the patient doctor relationship, not as a therapeutic relationship but as an interaction between provider and consumer, with cost effectiveness being the primary concern (Koh et al. 2000). Sadly, in recent years this situation has worsened with the economic downturn.

\footnotetext{
${ }^{1}$ The NHS Constitution. March 2013. London: Department of Health.

${ }^{2}$ Compassion in Practice, Nursing, Midwifery and Care Staff. Our Vision and Strategy (December 2012). DH/NHS Commissioning Board Gateway ref. 18479. Retrieved from www.commissi oningboard.nhs.uk/files/2012/12/compassion-in-practice.pdf.
} 
In the University Hospitals Bristol NHS Foundation Trust (UHBristol NHS Trust), in one of many initiatives across the NHS aiming to restore compassion to its rightful place in healthcare, a Compassion in Care Group (CCG) was formed. As part of its work, in order to determine staff views about compassionate care and to identify any training needs, an item was placed in the Trust's enewsletter inviting staff to respond to the question "What does compassion mean to you?" in an imaginative way, using reflective writing, poetry or drawings. It was hoped that a lasting piece of work could be produced, summarising what compassionate care actually looks and feels like, which could be shared with all users of the hospital services. The hospital-based CHEE was invited to help with this project as part of its ongoing research and educational development programme "Practising the Art of Wellbeing", which began in 1997 (Tsuboya et al. 2015). The programme aims to:

- Address clinical problems encountered with compassion fatigue and burnout;

- Support Human Resources and managerial needs associated with sickness absence and presenteeism and improve productivity;

- Foster greater enjoyment and pleasure in living and in one's work.

It also supports the increasing recognition within workplaces of the values to be gained from strengthened social capital ${ }^{1}$ (Tsuboya et al. 2015). The overall objective is to help show how the role and worth of engaging with the arts in health and wellbeing matters, and why and how "the art of compassionate care" is important to patients, NHS staff, managers, hospital visitors and the general public. Of particular relevance in NHS Occupational Health is that this objective picks up on concerns of the Department of Health for the health and wellbeing of NHS staff ${ }^{2}$. Another initiative by the Trust's CCG has been to introduce Schwarz Rounds (Goodrich 2011) to support staff since, as it noted on the Trust intranet: "the compassion shown by staff can make all the difference to a patient's experience of care, but in order to provide care with compassion staff must themselves feel supported in their work".

Another important aspect of compassion was touched on by one UH Bristol NHS Healthcare Trust staff member responding to the call for contributions, who wrote:

"In order to be compassionate we need to be compassionate with ourselves first and foremost and then with our colleagues, if we are to deliver compassionate care at the bed side. If we can't be nice to ourselves there's little chance we will be with other (sic)..."

Recent research within the "art of wellbeing model" suggests that the practice of self-compassion is the key to developing or increasing compassion towards

\footnotetext{
${ }^{1}$ Arts, Health and Wellbeing Beyond the Millennium: How far have we come and where do we want to go? Retrieved from fhttps://bit.ly/2qTvwUD.

${ }^{2}$ The Boorman Review: The Final Report of the Independent NHS Health and Wellbeing Review, 2009.
} 
others. Self-compassion entails self-kindness, the recognition of common humanity and mindfulness - a balanced awareness of present experience (Neff 2011). It is a skill which can be acquired and there is evidence that it increases emotional wellbeing and reduces stress reactions which can be a barrier to compassion for others (Neff 2011).

Compassionate practice in healthcare increases patient and staff satisfaction, and results in improved diagnosis, improved outcomes, fewer errors and complaints. However, the emotional drive to nurture, driven by the parasympathetic nervous system is overridden by the sympathetic drive of fear, fight and flight in the presence of perceived threat. An environment with fear as a dominant emotion erodes compassion and it is widely thought that recent NHS changes and the target driven culture diminish the ability for a culture of compassion to flourish.

It has been argued that compassion is unnecessary for competent care and that empathising too deeply with suffering patients can lead to burnout in healthcare workers (McClure 2013). However, studies of patient experience have demonstrated that the level of empathy needed in order for care to be experienced as compassionate need not be excessive. For example, the findings of a recent study of patients' experience of compassion in nursing care (Philipp et al. 2016) reported that "the smallest of nursing actions can convey compassion", and it was "the small things", "a few kind words" and "staff introducing themselves" which made them experience their care as compassionate. Staff who contributed their thoughts on compassion also included many small behaviours such as smiling, listening, holding a hand, giving full attention, making eye contact etc., all of which when used in the delivery of everyday tasks could make the patient feel valued, while their absence, for example "don't appear to listen", "didn't explain what she was doing", "make no apologies if they are late" could have the opposite effect (Philipp et al. 2015b).

The poems on compassion contributed in the above study by staff members at UH Bristol Trust are being reproduced for NHS staff and the public, in a small booklet to be entitled "Small Acts of Kindness: How we show compassion and how we experience it". The booklet will be illustrated with drawings on the same theme done by young patients in the Bristol Hospital for Children and with those of 7-10 year old children who are junior members of the St John Ambulance First Aid charity. It is hoped that these drawings will be displayed in a travelling exhibition for staff and visitors. After all, it is widely appreciated that young children use art spontaneously, having fundamental qualities that include imagination, enthusiasm, awe, wonder, spontaneous expression, creativity and imaginative play. From published findings of our studies to date of children's "art for health and wellbeing" (Philipp 1983, Philipp 1987, Philipp et al. 1984, Philipp et al. 1986) we believe that if as adults we could recapture these qualities and live a little more by them, while remaining mindful of the values of the natural environment, our health and wellbeing could benefit considerably. The proposed exhibition has these points in mind with its aim of helping to foster wider appreciation of the values of practising compassion in all areas of society. Indeed, as reported elsewhere, "the very term "humanitarian" denotes being caring and compassionate" (Ewen 2013). 


\section{Conclusions and Recommendations}

It is encouraging to see that since Bristol's first international conference on culture, health and wellbeing in 2013, action is being taken on so many fronts. In an increasingly insecure world, more work needs to be done to increase the resilience of individuals and communities and thereby strengthen their ability to cope with the changes life can bring. A suggested framework for this purpose is set out in the final section of the RSPH's report Arts, Health and Wellbeing beyond the Millennium: How far have we come and where do we want to go? ${ }^{1}$ So many aspects of the arts, heritage and the natural environment have the potential to contribute to this undertaking and we need too, to better appreciate that there is an art to exercising the science of public health (Thorpe \& Mackie 2012). The views expressed in this paper illustrate some of the ways in which we have found the arts to have a key role in health and wellbeing. They support findings of a new report, published in 2017, of the UK All Party Parliamentary Group on Arts, Health and Wellbeing ${ }^{2}$.

\section{Acknowledgements}

We are particularly grateful to colleagues in the Royal Society for Public Health, the Above and Beyond charitable Trust of University Hospitals Bristol NHS Trust and the Philipp Family Foundation for their encouragement and support of the work reported in this paper.

\section{References}

Adcroft L, Philipp R, Thorne P (2014) The NHS Constitution values are not always clearly expressed on Trust websites in England. Public Health 128(10): 948-951.

Aked J, Thompson S (2011) Five Ways to Wellbeing. New applications, new ways of thinking. London: New Economics Foundation and NHS Confederation.

Cameron M, Crane N, Ings R, Taylor K (2013) Promoting well-being through creativity: how arts and public health can learn from each other. Perspectives in Public Health 133(1): 52-59.

Camic PM, Chatterjee HJ (2013) Museums and art galleries as partners for public health interventions. Perspectives in Public Health, 133(1): 66-71.

Coughlin S (2006) Hope, ethics, and public health. Editorial. Journal of Epidemiology and Community Health 60(10): 826-827.

Department of Health (2010) Confident Communities, Brighter Futures. A framework for developing well-being. London: Department of Health, Mental Health Division.

Eames P (2007) Cultural Well-Being and Cultural Capital. Electronic book: PSE Consultancy with Arts Access International. Retrieved from https://bit.ly/2HtG5bb.

\footnotetext{
${ }^{1}$ Arts, Health and Wellbeing Beyond the Millennium: How far have we come and where do we want to go? Retrieved from fhttps://bit.ly/2qTvwUD.

${ }^{2}$ The All Party Parliamentary Group on Arts, Health and Wellbeing, 2017. Creative Health:

The Arts for Health and Wellbeing. Retrieved from https://bit.ly/2vCJQWA.
} 
Eames P (2003) Creative Solutions and Social Inclusion: Culture and the Community. Wellington: Steele Roberts.

Ewen J (2013) A celebration of Scotland - Malawi Youth Links: building international connections for a better world for better health. Perspectives in Public Health 133(3): 139.

Goodlad R, Hamilton C, Taylor PD (2002) Not Just a Treat: Arts and Social Inclusion. A report to the Scottish Arts Council. Scotland: University of Glasgow. Retrieved from https://bit.ly/2Ij9K6y.

Goodrich J (2011) Schwartz Centre Rounds. Evaluation of the UK Pilots. London: The King's Fund.

Grimm Jr. R, Spring K, Dietz N (2007) The Health Benefits of Volunteering. A review of recent research. Washington: Office of Research and Policy Development, Corporation for National and Community Service.

Hamilton C, Hinks S, Petticrew M (2003) Arts for health: still searching for the Holy Grail. Public Health Policy and Practice. Journal of Epidemiology and Community Health 57(6): 401-402.

Health Education Authority (2000) Art for health. A review of good practice in community-based arts projects and interventions which impact on health and well-being. London: HDA.

Koh D, Chia SE, Jeyaratnam J (2000) Occupational medicine in the 21st century: A South-East Asian perspective. Occupational Medicine 50(1): 64-73.

Lord Darzi (June 2008) High Quality Care for All. NHS Next Stage Review. London: Department of Health.

Marmot Review Team (2010) Fair Society, Healthy Lives: A Strategic Review of Health Inequalities in England Post-2010. London: The Marmot Review Team.

Marmot M, Bell R (2012) Fair society, healthy lives. Public Health 126(Suppl. S1): S4-S10.

McClure R (February 28, 2013) Sustaining compassion in healthcare. Retrieved from https://bit.ly/2r5I1g7.

Mooney G (1995) Book Review: Social Dimensions of Health and Disease. New Zealand perspectives. Australian Journal of Public Health 19(3): 318-319.

Neff K (May 27, 2011) Why self compassion trumps self-esteem. Retrieved from https://bit.ly/2E1TN0g.

NHS Executive (January 15, 1999) Healthy living centres. Health Service Circular. London: Department of Health.

Philipp R (2012) Fostering the art of wellbeing: an alternative medicine. In A Bhattacharya (Eds.), A Compendium of Essays on Alternative Therapy. Croatia InTech. Retrieved from https://bit.ly/2FpYsrY.

Philipp R (2010) Making sense of wellbeing. Perspectives in Public Health 130(2): 58.

Philipp R (2007) The Anthropology of Humanitarian Aid: all the unwritten rules. In LE Pacifici, F Riccardo (Eds.), Technology and Communication for a New Humanitarian Intervention. Italy: FrancoAngeli.

Philipp, R (2002) Arts, Health, and Well-Being: From the Windsor I Conference to a Nuffield Forum for the Medical Humanities. London: The Nuffield Trust. Retrieved from https://bit.ly/2HCnTs4.

Philipp R (1999) Evaluating the arts in healthcare and mental health promotion: the example of creative writing. In D Haldane and S Loppert (Eds.), The Arts in Healthcare: Learning from Experience. London: Kings Fund.

Philipp R (1987) Through a child·s eyes. Good Health 2(Feb/Mar.): 32-33.

Philipp R (1983) Children of the nuclear age. The Lancet 322(Aug.): 457. 
Philipp R, Thorne P (2015) Heritage and the public health: releasing the wellbeing held in museums. Journal of Education in Museums 36: 3-18.

Philipp R, Thorne P, Watkin T, Morgan H, Witherston J (2016) Patient Views on Compassion: for comparison with staff views. A referenced Working Paper. [available on request from the first author].

Philipp R, Gibbons N, Thorne P, Wiltshire L, Burrough J, Easterby J (2015a) Evaluation of a community arts installation event in support of public health. Perspectives in Public Health 135(1): 43-48.

Philipp R, Thorne P, Morgan H, Witherstone J (2015b) What Compassion Means to NHS staff: An overview and analysis of responses to the UHBristol NHS Trust Compassion in Care Group initiative, including suggestions for further study. A fully-referenced Working Paper. [available on request from the first author]

Philipp R, Sherwin P, Buxton R, Sherwin J, Mackle I, Mackle R (2013) Foreword. Wai Ora. Water Life: Te Horo to Otaki. Children's Creations. Waikanae, New Zealand: Mahara Gallery.

Philipp R, Sherwin P, Buxton R (2012) Everything in life is connected. Public Health 126 (Suppl. S1): S68-S69.

Philipp R, Baum M, Mawson A, Calman Sir K (1999) Humanities in Medicine: Beyond the Millenium. A summary of the proceedings of the first Windsor Conference. Nuffield Trust Series No. 10. London: The Nuffield Trust. Retrieved from https://bit. ly/2JuJT8P.

Philipp R, Philipp E, Pendered L, Barnard C, Hall M (1986) Can children's paintings of their family doctor be interpreted? Journal of the Royal College of General Practitioners 36(288): 325-327.

Philipp R, Philipp E, Pullon S, Graham A (1984) Interpreting children's paintings of their doctors. NZ Family Physician 11(1): 23-24.

Porritt J (2012) No sustainability without health equity. Public Health 126(Suppl. S1): S24-S26.

Rees L, Weil A (2001) Integrated medicine. British Medical Journal 322(Jan.): 119-120.

Secretary of State for Health (1992) The Health of the nation: a strategy for health in England. London: HMSO.

Thorpe A, Mackie P (2012) Guest Editorial. Let's dance. Public Health 126(Suppl. S1): S2-S3.

Tsuboya T, Tsutsumi A, Kawachi I (2015) Change in psychological distress following change in workplace social capital: results from the panel surveys of the J-HOPE study. Occupational and Environmental Medicine 72(3): 188-194.

WHO-World Health Organisation (1981) Global strategy for health for all by the year 2000. Geneva: WHO. 